\title{
MITI makes its move
}

\section{Arita}

Winlle the western press has noted at length Japan's efforts to develop practical high-temperature ceramic oxide superconductors, less attention has been paid to the even greater effort Japanese industry and government are pouring into the development of other advanced ceramics, notably ceramic/carbon fibre composites that will be strong and light enough to make the outer skin of space planes and hypersonic aircraft. In a talk on composite ceramics at an international conference last week in Arita, on Japan's island of Kyushu, R. W. Davidge of the UK Harwell Laboratory said that "of the 5,000 copies of my book sold worldwide, half have been sold in Japan." Last year, the Ministry for International Trade and Industry (MITI) moved into the area with a new project under its programme of "research and development of basic technologies for future industries" (jiseidai), and the materials are among the latest subjects for study at MITI's laboratories in Nagoya and Kyushu.

These new ceramics, hard and heatresistant, have a huge range of applications, from car parts to false teeth. Hundreds of Japanese companies are pushing their development, with activity particularly concentrated in the Nagoya area, the traditional centre of Japan's pottery industry and the home ground of Toyota.
In 1985, over 300 Japanese companies donated a total of $¥ 5,900$ million ( $\$ 45$ million) to establish the Japan Fine Ceramics Center (JFCC) in Nagoya. With backing from MITI and more money from the local governments of Nagoya, and Aichi and Gifu prefectures, JFCC has become a state-of-the-art centre for ceramics research, performing commissioned research to a value of $¥ 700$ million $(\$ 5.4$ million) a year

Automobile manufacturers are particularly keen to develop lighter more fuelefficient cars using ceramic materials. Ceramic turbochargers are already used in some Japanese-made cars, but mass production of ceramic engine components has been problematic because of poor yield and disparities in strength. And ceramics cost $¥ 5,000$ to $¥ 10,000$ a kilogram compared with a few hundred yen a kilogram for steel. One of the key aims of $\mathrm{JFCC}$ is to help bring down these costs by developing standard testing, inspection and evaluation techniques.

In addition to the JFCC, MITI established several other jiseidai projects in the 1980 s to support ceramic research, such as the 'high performance ceramics' programme, focusing on on the development of silicon nitride and silicon carbide ceramics for use as high-temperature components in gas turbine engines. Japan, with 50 per cent of worldwide sales,

\section{Punishment for success}

\section{Arita}

Alrhough MITI is pouring support into ceramic research, a MITI-backed researcher who made a breakthrough in the development of ceramics earlier this year, found that the system had a very odd way of rewarding excellence.

When Fumihiro Wakai, senior researcher of the ceramic science department of MITI's Government Industrial Research Laboratory in Nagoya (GIRIN) announced the development of the world's first superplastic crystal composite ceramic in March (Nature, 344, 421-423; 1990) he was flooded with enquiries from overseas, particularly from the US defence establishment, according to Sakae Tanemura, senior officer of research planning at GIRIN

But Wakai complains that although he has been supported with funds of $¥ 20$ million $(\$ 154,000)$ a year for the past three years his research budget has now been slashed to $¥ 400,000(\$ 3,000)$ a year. He says that his case is not exceptional and that it reveals defects in the system of research grant allotment in MITI's laboratories.

Wakai says his funding was cut because his department has received a lot of financial support in the past few years, and the "democratic" system in MITI's institutes now dictates that more money must be funnelled into the other five departments.

In obtaining research funds the chief hurdle to overcome, according to Wakai, is the internal screening of research proposals in the institute before they are submitted to MITI's Agency of Industrial Science and Technology (AIST); for standard research grants researchers cannot apply directly to AIST for support. Wakai is now looking into the possibility of applying for funds through a special interministry programme run by the Science and Technology Agency (STA). Applications for the STA programme do not have to be internally screened in the institute but competition for the limited number of grants is severe.

Wakai contrasts AIST's system with that of the US National Science Foundation), to which researchers apply directly. Grant proposals are reviewed by outside reviewers, sometimes from overseas, a system that Wakai hopes will one day be adopted in Japan.

David Swinbanks already dominates the carbon fibre production market, and has strong capability in the development of new materials -- both PAN (polyacrylonitrile) and pitch-based carbon fibre were invented in Japan. Yasuhiro Yamada, of MITI's Government Industrial Research Institute in Tosu Kyushu, says that Japan started this kind of research late compared with the United States and Europe. But MITI has organized a research consortium of 12 companies, including Nissan, Nippon Oil Company, and Toa Nenryo Kogyo, an oil refiner that is pushing development of pitch-based carbon fibre, to develop composite ceramics. And given Japan's tremendous strengths in both ceramic and carbon fibre research it will not be long before Japanese companies catch up with the West.

David Swinbanks COMPUTER RESEARCH

\section{Artificial postmen}

\section{Washington}

NeXT time you scrawl an address on an envelope, consider what you may be asking an automated mail-sorting machine to do. After satisfying itself that your scribble is indeed an address, it scans for something resembling a postal or zip code. On the rare occasions when it finds one, it then tries to determine a delivery route by deciphering as much of the street address as it can. Needless to say, failure is common; only 4 per cent of handwritten mail (which accounts for some 15 per cent of the US mailstream) can now be machine-read by the US postal service.

Technology now being developed is better - it can read some three-quarters of the handwritten letters it sees - but takes two to three minutes to scrutinize each piece.

Dissatisfied with progress in machine reading after some 15 years of research, the US postal service last week decided to try something new. It announced plans to set up its first "research centre of excellence", a permanent computer vision laboratory at the State University of New York, Buffalo, where researchers have been working on the problem for several years. With initial funding between $\$ 2$ and $\$ 3$ million per year, the centre is aiming at artificial-intelligence and neural-networkbased machines that can read 12 or 13 pieces of handwritten mail per second, says associate director Jonathan Hull. Working prototypes could be ready in as little as a year or two, he says. Among the top research priorities will be the use of "contextual analysis" to decipher a problem character or word based on those around it, and to compensate for missing or incorrect postal codes by making a sensible guess based on other address elements.

Christopher Anderson 